\title{
IL6 blockade potentiates the anti-tumor effects of $\gamma$-secretase inhibitors in Notch3-expressing breast cancer
}

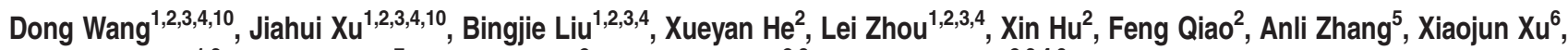 \\ Huafeng Zhang ${ }^{1,3}$, Max S Wicha ${ }^{7}$, Lixing Zhang ${ }^{2}$, Zhi-ming Shao ${ }^{2,8}$ and Suling Liü ${ }^{\star 2,3,4,9}$
}

Notch pathways have important roles in carcinogenesis including pathways involving the Notch1 and Notch2 oncogenes. PanNotch inhibitors, such as gamma secretase inhibitors (GSIs), have been used in the clinical trials, but the outcomes of these trials have been insufficient and have yielded unclear. In the present study, we demonstrated that GSIs, such as MK-0752 and R04929097, inhibit breast tumor growth, but increase the breast cancer stem cell (BCSC) population in Notch3-expressing breast cancer cells, in a process that is coupled with IL6 induction and is blocked by the IL6R antagonist Tocilizumab (TCZ). IL6 induction results from inhibition of Notch3-Hey2 signaling through MK-0752. Furthermore, HIF1 $\alpha$ upregulates Notch3 expression via direct binding to the Notch3 promoter and subsequently downregulates BCSCs by decreasing the IL6 levels in Notch3-expressing breast cancer cells. Utilizing both breast cancer cell line xenografts and patient-derived xenografts (PDX), we showed that the combination of MK-0752 and Tocilizumab significantly decreases BCSCs and inhibits tumor growth and thus might serve as a novel therapeutic strategy for treating women with Notch3-expressing breast cancers.

Cell Death and Differentiation (2018) 25, 330-339; doi:10.1038/cdd.2017.162; published online 13 October 2017

The Notch signaling pathway has a fundamental role in development across all metazoan species. Previous studies have demonstrated that the Notch signaling pathway regulates cell differentiation, proliferation and apoptosis in cancer. ${ }^{1}$ Additional studies have demonstrated that Notch also regulates stem cells. ${ }^{2,3}$ For example, lung cancer stem cells display higher Notch expression than bulk tumor cells, and Notch3 has been shown to be a key driver of stemness. ${ }^{4,5}$ Notch signaling also contributes to the maintenance of BCSC stemness. Several studies have demonstrated that Notch promotes tumor cell proliferation and migration by increasing breast cancer stem cells. ${ }^{6}$

Although the Notch signaling pathway has been widely studied, ${ }^{7}$ the specific role of the individual Notch receptor is still unclear. Previous studies have suggested that Notch4 has a specific role in regulating breast cancer stem cells ${ }^{6}$ and Notch4 knockdown decreases tumor formation in breast cancer cells. ${ }^{8}$ Most studies concerning individual Notch receptors have focused on Notch1 and Notch2. ${ }^{9,10}$ However, there were few studies have specifically examined the role of Notch3. ${ }^{5}$

To block the adverse function of Notch signaling in cancers, a number of Notch inhibitors have been developed, several of which have entered clinical trials. However, in addition to potential toxicity, simultaneous inhibition of multiple Notch receptors may have pleiotropic effects resulting from tumor stimulation. ${ }^{11}$ These findings indicate that there might be a contrary function of Notch receptors in cancer. In the present study, we explored the role and mechanisms of pan-Notch inhibitor gamma secretase inhibitors (GSIs) in regulating breast cancer stem cells in Notch3-expressing breast cancer. Importantly, we identified a novel combinational therapeutic approach to overcome the unsatisfying effects of GSIs on Notch3-expressing breast cancer.

\section{Results}

GSI increases the breast cancer stem cell population by inducing IL6. Because most studies have shown that Notch signaling promotes tumor growth and progression, a number of Notch inhibitors have been developed and entered clinical trials. Among the first agents developed were GSIs. ${ }^{12} \mathrm{~A}$ limitation of GSIs is that these compounds inhibit the activities of all four Notch receptors, thus potentially affecting their efficacy because different Notch receptors may mediate diverse effects in addition to having potential toxicity. In

${ }^{1}$ Hefei National Laboratory for Physical Sciences at the Microscale, School of Life Science, University of Science \& Technology of China, Hefei, Anhui, China; ${ }^{2}$ Key Laboratory of Breast Cancer in Shanghai, Cancer Institute, Department of Breast Surgery, Fudan University Shanghai Cancer Center, Shanghai 200032, China; ${ }^{3}$ Innovation Center for Cell Signaling Network, School of Life Sciences, Xiamen University, Xiamen, Fujian 361102, China; ${ }^{4}$ The CAS Key Laboratory of Innate Immunity and Chronic Disease, University of Science \& Technology of China, Hefei, Anhui 230027, China; ${ }^{5}$ Department of Pathology, Anhui Provincial Hospital, Southern District, Hefei, Anhui, China; ${ }^{6}$ The Department of Breast Surgery, The First Affiliated Hospital, Anhui Medical University, Hefei, Anhui, China; ${ }^{7}$ University of Michigan Comprehensive Cancer Center, Ann Arbor, MI, USA; ${ }^{8}$ Department of Oncology, Shanghai Medical College, Fudan University, Shanghai, China and ${ }^{9}$ Institutes of Biomedical Sciences, Fudan University, Shanghai, China

*Corresponding author: S Liu, Key Laboratory of Breast Cancer in Shanghai, Cancer Institute, Department of Breast Surgery, Fudan University Shanghai Cancer Center, 270 Dong An Road, Shanghai 200032, China; Tel/Fax: +86-21-34771023. E-mail: suling @fudan.edu.cn

${ }^{10}$ These authors contributed equally to this work

Received 02.5.17; revised 23.8.17; accepted 29.8.17; Edited by Y Shi; published online 13.10.17 
a
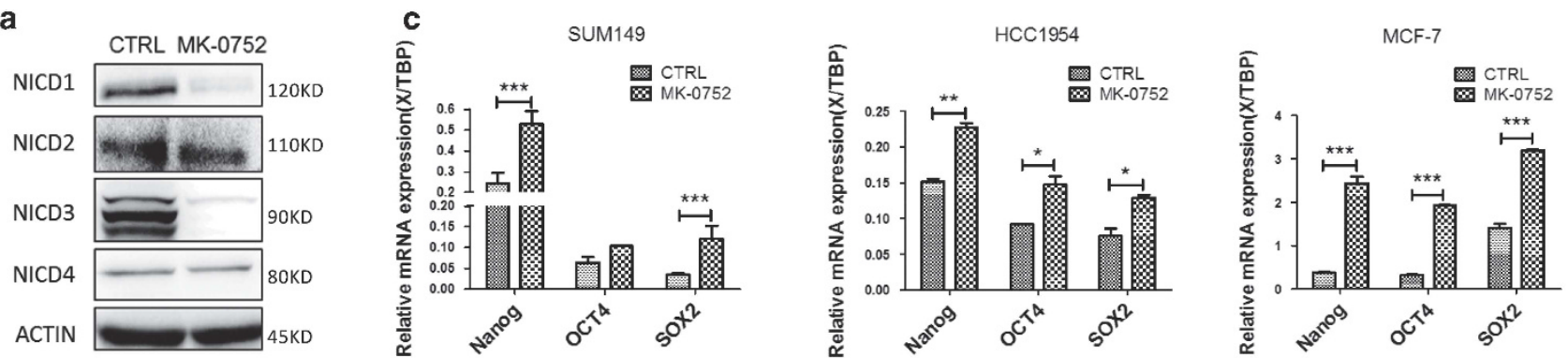

b $\quad$ SUM149
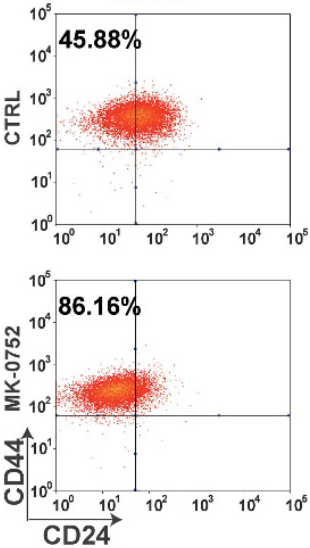

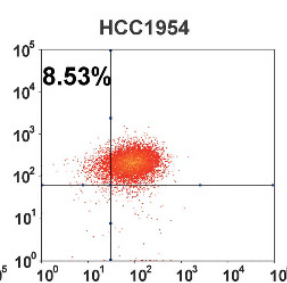

${ }_{10^{4}}^{10^{5}} 20.98 \%$

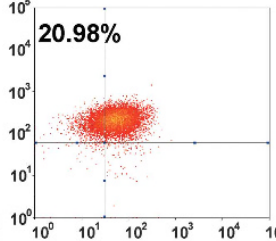

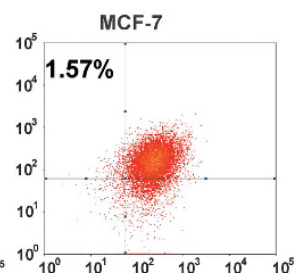

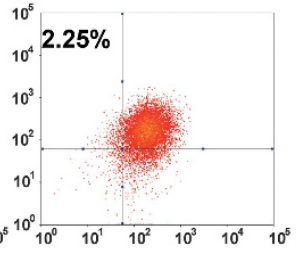

d

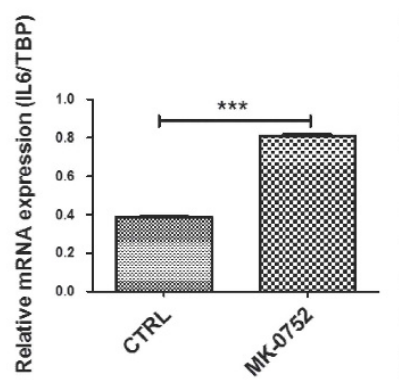

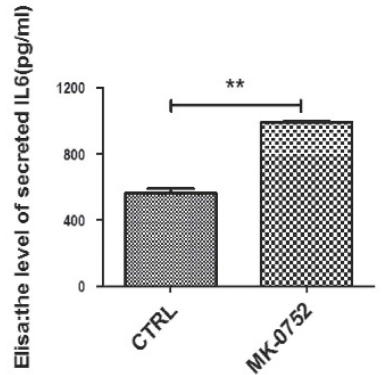

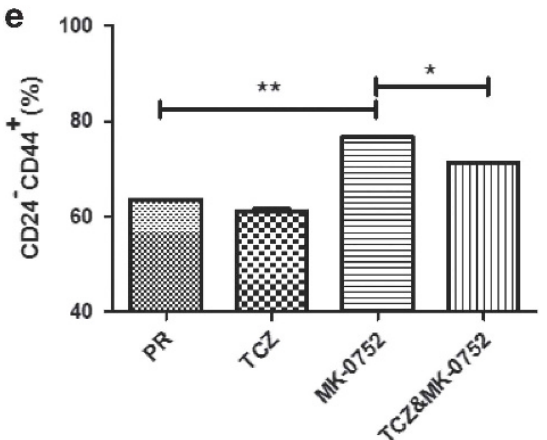

f
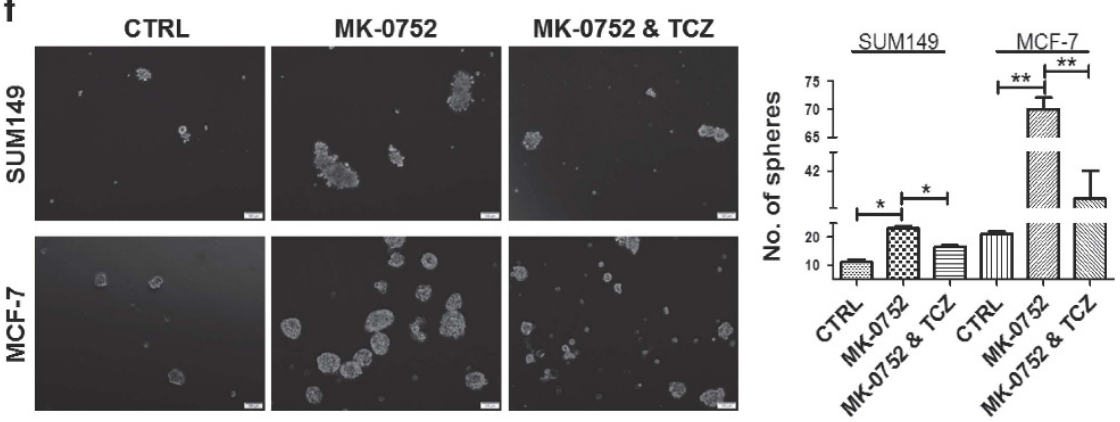

Figure 1 The gamma secretase inhibitor (GSI) MK-0752 increases the breast cancer stem cell population by inducing IL6. (a) SUM149 cells were treated with MK-0752 for 7 days or left untreated, and the NICD level was detected using western blot analysis. (b) Cells were cultured in the absence or presence of MK-0752 for 7 days. After treatment, the cells were analyzed for CD24 and CD44 by using flow cytometry. (c) Nanog, Sox2, OCT4 were detected in the cells treated with MK-0752 for 7 days by using qRT-PCR. ${ }^{*} P<0.05,{ }^{* \star} P<0.01,{ }^{* \star} P<0.001$. TBP (the gene encoding TATA box binding protein) was used as a control. (d) MK-0752 treatment induces IL6 mRNA expression (left) and secretion (right) in SUM149 cells. ${ }^{*} P<0.05,{ }^{* *} P<0.01,{ }^{* * *} P<0.001$. (e) The percentage of CD24-CD44 ${ }^{+}$was detected by using flow cytometry in SUM149 cells treated with MK-0752, TCZ or combination. ${ }^{*} P<0.05,{ }^{* \star} P<0.01,{ }^{* \star} P<0.001$. (f) Primary sphere-forming capacity of cells in low-density suspension culture with different treatments. ${ }^{\star} P<0.05,{ }^{* \star} P<0.01,{ }^{* \star *} P<0.001$

addition, the recent failure of a clinical trial using the antibody Tarextumab, which blocks both Notch2 and Notch3 (Oncomed Pharmaceuticals), to treat advanced pancreatic cancer prompted us to investigate the potential mechanism underlying this failure to develop a better therapeutic approach for Notch-expressing tumors. We examined the effects of the GSIs MK-0752 and RO4929097 $7^{13-15}$ on Notch signaling in breast cancer cell lines. MK-0752 treatment decreased the expression of Notch intracellular domain 1-3 (NICD1-3) of Notch receptors (Figure 1a; Supplementary Figures $1 a, b)$ in breast cancer cell lines, thus resulting in inhibition of the Notch downstream effectors Hes1, Hes2, Hey1 and Hey2 (Supplementary Figure 1c). We also treated
SUM149 and MCF-7 with RO4929097, and found that R04929097 also effectively decreased expression of NICD1-3 (Supplementary Figure 1d). MK-0752 effectively inhibited proliferation of SUM149, MCF-7 and HCC1954 cells (Supplementary Figure 2a), in a manner not mediated by induction of apoptosis (Supplementary Figure 2b). Although MK-0752 decreased cell proliferation, a significant increase in the CD24-CD44 ${ }^{+}$BCSC population in the analyzed breast cancer cell lines was observed (Figure 1b). Furthermore, MK-0752 treatment significantly upregulated the expression of stem cell genes Nanog, Sox2, Oct4 in cancer cells (Figure 1c) and increased mammosphere formation (Figure 1f), thus indicating that MK-0752 treatment might 


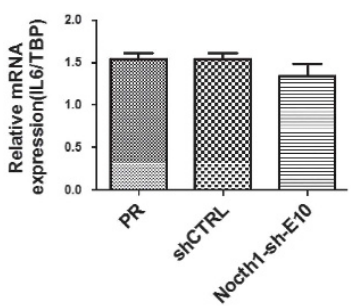

b

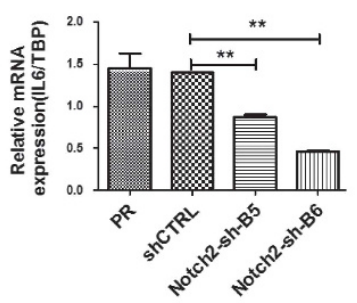

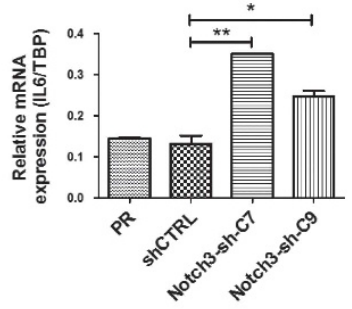

h

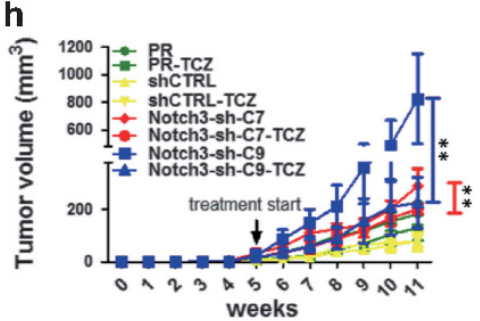

f

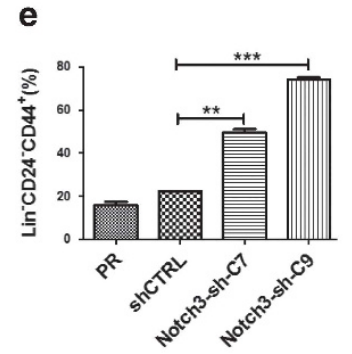

f $P R$

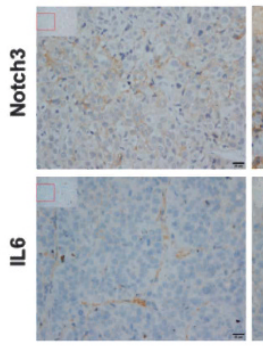

i

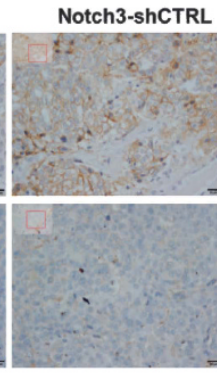

pSTAT3

ACTIN
Notch3-sh-C7

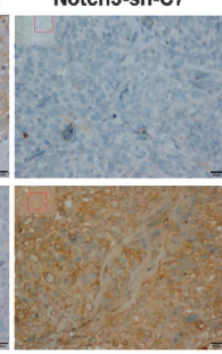

Notch3-sh-C9
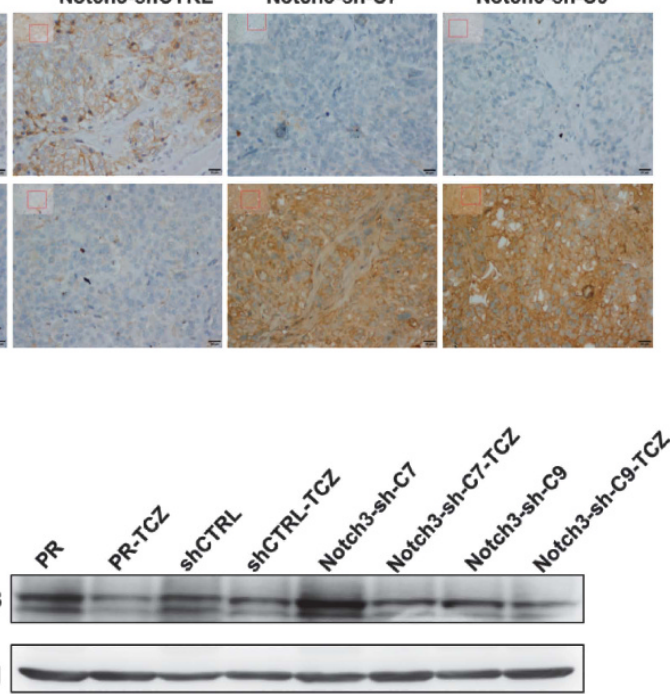

d

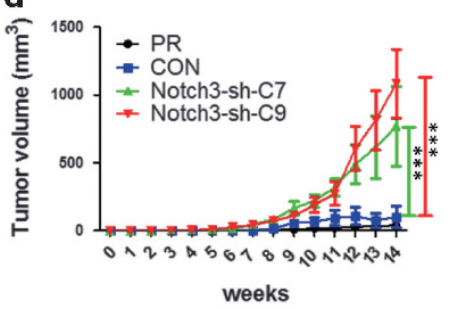

g

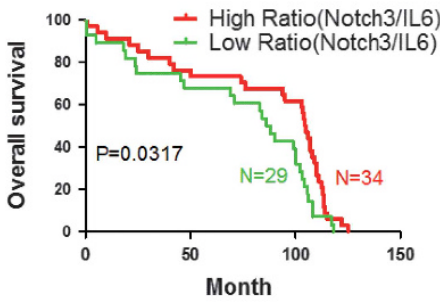

j

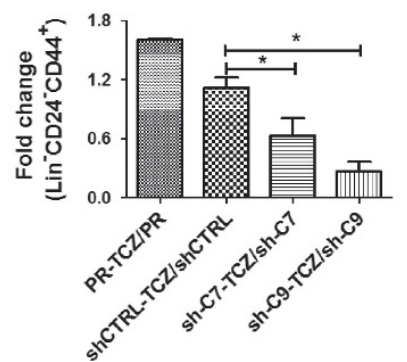

Figure 2 Notch3 knockdown promotes breast tumor growth by inducing IL6 and activating STAT3. (a-c) mRNA expression of IL6 was detected by using qRT-PCR in the SUM149-Notch1 knockdown cell line (Notch1-sh-E10) (a), SUM149-Notch2 knockdown cell lines (Notch2-sh-B5, Notch2-sh-B6) (b) and SUM149-Notch3 knockdown cell lines (Notch3-sh-C7, Notch3-sh-C9) (c). ${ }^{*} P<0.05,{ }^{* *} P<0.01,{ }^{* \star *} P<0.001$. (d) Each group of SUM149 cells (Parental (PR), shCTRL, Notch3 knockdown) was injected into both sides of the 4th mammary gland fatpads of three nude mice (2000 cells per injection site). The tumor sizes were monitored, measured weekly, and calculated with the formula tumor volume $=$ length $\times$ width $2 / 2 .{ }^{*} P<0.05,{ }^{* *} P<0.01,{ }^{* * *} P<0.001$. (e) The tumors in $\mathrm{d}$ were dissociated into single cells and were analyzed for Lin ${ }^{-} \mathrm{CD} 24^{-} \mathrm{CD} 44^{+}$by using flow cytometry. Lin ${ }^{-}$refers to $\mathrm{CD}^{-} 5^{-}, \mathrm{CD} 31^{-}, \mathrm{CD} 140 \mathrm{~b}^{-}, \mathrm{CD} 235 \mathrm{a}^{-}$and H2Kd ${ }^{-}{ }^{*} P<0.05,{ }^{* \star} P<0.01,{ }^{* \star *} P<0.001$. (f) The tumors in d were analyzed for Notch3 and IL6 by using IHC staining. (g) The correlation between the ratio of Notch3/L6 protein level in breast cancer tissues and patients' overall survival was analyzed. The thresholds were defined according the following rules: High ratio - Ratio 3 or greater and expression of Notch3 was greater than or equal to 2 to prevent the low expression of Notch3 itself, but IL6 expression was even lower, thus leading to the high ratio; Low ratio - Ratio 1 or less and expression of Notch3 was lower than or equal to 1 to prevent the high expression of Notch3 itself, but IL6 expression was even higher, thus leading to the low ratio. (h) Each group of SUM149 cells was injected into both sides of the 4th mammary gland fatpads of the nude mice (2000 cells per injection site). The tumors were treated with vehicle control or the IL6 antagonist Tocilizumab (TCZ). The tumor sizes were monitored and measured weekly. ${ }^{*} P<0.05,{ }^{* *} P<0.01,{ }^{* \star *} P<0.001$. (i) The tumors in $\mathbf{h}$ were analyzed for $\mathrm{pSTAT} 3$ by using western blot analysis. (j) The tumors in $\mathbf{h}$ were dissociated into single cells and were analyzed for $\mathrm{Lin}^{-} \mathrm{CD} 24^{-} \mathrm{CD} 44^{+}$by using flow cytometry. ${ }^{*} P<0.05$

enrich breast cancer stem cells in breast cancer cell lines. To confirm this finding, we used RO4929097 to treat SUM149 and MCF-7. RO49097 increased the CD24 CD44 ${ }^{+}$BCSC population (Supplementary Figure $3 \mathrm{a}$ ), increased the mammosphere formation (Supplementary Figure $3 b$ ) and induced the expression of stem cell genes (Supplementary Figure 3c).

Previous studies have reported that inflammatory factors regulate breast cancer stem cell self-renewal ${ }^{16,17}$ and promote tumor progression. ${ }^{18}$ Therefore, we investigated whether MK-0752 upregulates breast cancer stem cells by inducing inflammatory factors, such as IL1, IL2, IL4, IL5, IL6, IL7, IL10, CCL2 and CCL3. The data showed that, among the inflammatory factors analyzed, IL6 expression was significantly induced by MK-0752 treatment (Figure 1d; Supplementary Figures 4a,b). RO4929097 treatment also induced expression of IL6 in SUM149 and MCF-7 (Supplementary Figure 5). Simultaneously treating cells with MK-0752/RO4929097 and the IL6 receptor antagonist Tocilizumab (TCZ) showed that TCZ abrogated the increase in the $\mathrm{CD}^{-} 4^{-} \mathrm{CD} 44^{+}$population induced by MK-0752/RO4929097 (Figure 1e; Supplementary Figures $6 a, b$ and $3 a$ ). Furthermore, TCZ also abrogated the stimulation of mammosphere formation by MK-0752 (Figure 1f; Supplementary Figure 3b). These findings demonstrated that IL6 mediates the enrichment of the $\mathrm{CD} 24^{-} \mathrm{CD} 44^{+} \mathrm{BCSC}$ population induced by MK-0752 treatment. 
Notch3 knockdown promotes breast tumor growth by inducing IL6 and activating STAT3. In the treatment of tumors, because the primary role of GSIs is inhibition of Notch signaling, and MK-0752 treatment upregulates IL6, MK-0752 might regulate IL6 by inhibiting certain Notch receptors. In contrast to the findings reported above, previous studies have shown that inhibition of Notch1 and Notch4 decreases the BCSC population., ${ }^{6,19}$ MK-0752 inhibited NICD1, NICD2 and NICD3 but not NICD4 in the present study system (Figure 1a; Supplementary Figures 1a,b). In addition, Tarextumab from Oncomed pharmaceuticals simultaneously inhibited Notch2 and Notch3. On the basis of these studies, we speculated that the effect of different Notch receptors might be different in terms of regulating cancer progression, thus leading to poor clinical outcomes. To confirm this hypothesis, we established Notch1, Notch2 or Notch3 knockdown cell lines, because MK-0752 had little effect on Notch4 in the present system (Figure 1a; Supplementary Figures $1 a, b)$, and the results showed that Notch1 knockdown had no effect on IL6 expression, whereas Notch2 knockdown inhibited IL6 expression, and Notch3 knockdown induced IL6 expression (Figures 2a-c; Supplementary Figures 7a,b). To determine whether the observed effects of MK-0752 on BCSCs and IL6 were Notch3 dependent, we measured the expression of Notch3 in different subtypes of breast cancer cell lines and observed that Notch3 expression was higher in lower tumorigenic cell lines (BT474, SKBR-3, MCF-7 and SUM149) compared with highly tumorigenic and invasive cell lines (SUM1315, SUM159 and MDA-MB-231), as measured through both qRT-PCR (Supplementary Figure 8a) and flow cytometry (Supplementary Figure 8b). Because the activation of Notch signaling is dependent on active Notch (NICD), ${ }^{20}$ we assessed NICD3 by using western blot analysis and observed that NICD3 expression was much higher in lower tumorigenic cell lines than in higher tumorigenic and invasive cell lines (Supplementary Figure 8c). Because MDA-MB-231 has low Notch3 expression, we treated MDA-MB-231 with MK-0752 for 7 days as a negative control and found that IL6 was not upregulated (Supplementary Figure 9a) by this treatment, whereas the proportion of BCSCs was decreased (Supplementary Figure 9b). These data indicated that Notch3 might have a key role in mediating IL6 induction and increasing BCSCs through MK-0752 treatment. Furthermore, we performed immunochemistry in 132 breast tumors tissue samples by utilizing a Notch3 specific antibody and observed that low Notch3 expression was correlated with the poor overall survival of patients (Supplementary Figures 10a,b; Supplementary Table 1), in agreement with the results for breast cancer cell lines.

To further determine the effects of Notch3 on breast tumor growth and to explore the role of Notch3 in regulating breast cancer stem cells in vivo, we injected SUM149-Notch3 knockdown cell lines into at least three mice, with two injection sites per mouse ( 200 cells or 2000 cells per injection site), and the experiments were repeated twice. The knockdown efficiency was confirmed, as shown in Supplementary Figure 11a, and Notch3 knockdown has little or no effect on other Notch receptors (Supplementary Figures 11b,c,d). The results showed that Notch 3 knockdown significantly promoted tumor growth (Figure 2d; Supplementary Figures 12a,b) and increased the $\mathrm{Lin}^{-} \mathrm{CD} 24^{-} \mathrm{CD} 44^{+}$population by at least $2-3$ fold (Figure 2e; Supplementary Figure 12c). These results suggested that Notch3 might act as a tumor suppressor and inhibit breast cancer stem cell self-renewal.

Together with previous reports that IL6/STAT3 upregulates Notch3, ${ }^{21,22}$ our results suggested that Notch3 might form a negative feedback loop with IL6/STAT3 signaling. To confirm whether the increase of the IL6 level was correlated with Notch3 downregulation in breast tumors, we examined the expression of both Notch3 and IL6 by using IHC in the xenograft tumor specimens grown from the breast cancer cell line SUM149 with or without Notch3 knockdown in mice. As shown in Figure 2f, IL6 expression was higher in tumors generated from Notch3 knockdown cells than the controls, thus suggesting that Notch3 negatively regulates IL6 expression in breast tumors. Furthermore, analysis of the Notch3 and IL6 protein expression in 132 clinical breast tumors (Supplementary Table 1), revealed that the ratio of Notch3/ IL6 staining score was positively correlated with the overall survival of the patients (Figure $2 \mathrm{~g}$ ). Analysis of the TCGA database also showed that patients with a higher Notch3/IL6 mRNA expression ratio had more favorable overall survival compared with those with a low ratio (Supplementary Figure 13), thus suggesting that Notch3 might negatively regulate IL6, showing an opposite correlation with the malignancy of breast cancer.

We next determined whether the effects of Notch3 knockdown on BCSCs and subsequent tumor growth were mediated by IL6. Notch3 knockdown or control breast cancer cells were injected into the mammary fatpads of nude mice, and the established tumors were randomly divided into two groups with similar tumor volumes and treated with the IL6R antagonist Tocilizumab (TCZ). As shown in Figure 2h, Notch3 knockdown stimulated tumor growth, but TCZ significantly decreased the growth of tumors generated from Notch3 knockdown cells, as compared with that in mice treated with vehicle control. Furthermore, immunohistochemistry showed that Notch3 knockdown increased expression of pSTAT3, a downstream target of IL6 signaling. TCZ dramatically decreased pSTAT3 expression in tumors derived from Notch3 knockdown (Figure 2i). In addition, TCZ decreased the $\mathrm{Lin}^{-} \mathrm{CD} 24^{-} \mathrm{CD} 44^{+}$population in tumors derived from Notch3 knockdown, but not in the parental tumors or ShCTRL cells. These results suggested that the effects of Notch3 on BCSCs and subsequent tumor growth are mediated by IL6/STAT3 signaling and that these effects can be abrogated by using the IL6R inhibitor TCZ (Figure 2j).

Hey2 mediates IL6 induction by Notch3 knockdown. Because IL6 expression was significantly upregulated only when Notch3 was inhibited, we assessed the changes in the downstream genes Hes1, Hes2, Hes7, Hey1 and Hey2 in the Notch signaling pathway by using qRT-PCR in Notch1, Notch2 or Notch3 knockdown cells and observed that Hey2 was decreased exclusively in Notch3 knockdown cells (Figures 3a-c; Supplementary Figures 14a,b,c). To determine whether Hey2 is the key mediator for IL6 induction by Notch3 knockdown, we established Hey2 knockdown cell lines (Supplementary Figure 15a) and observed that Hey2 
a
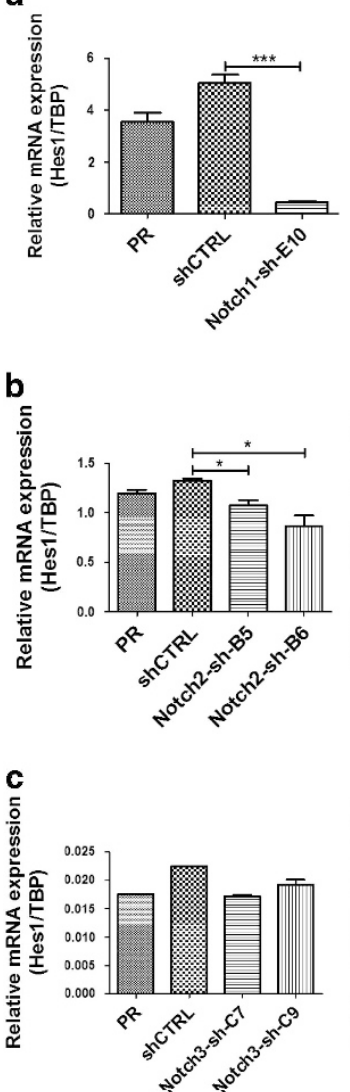
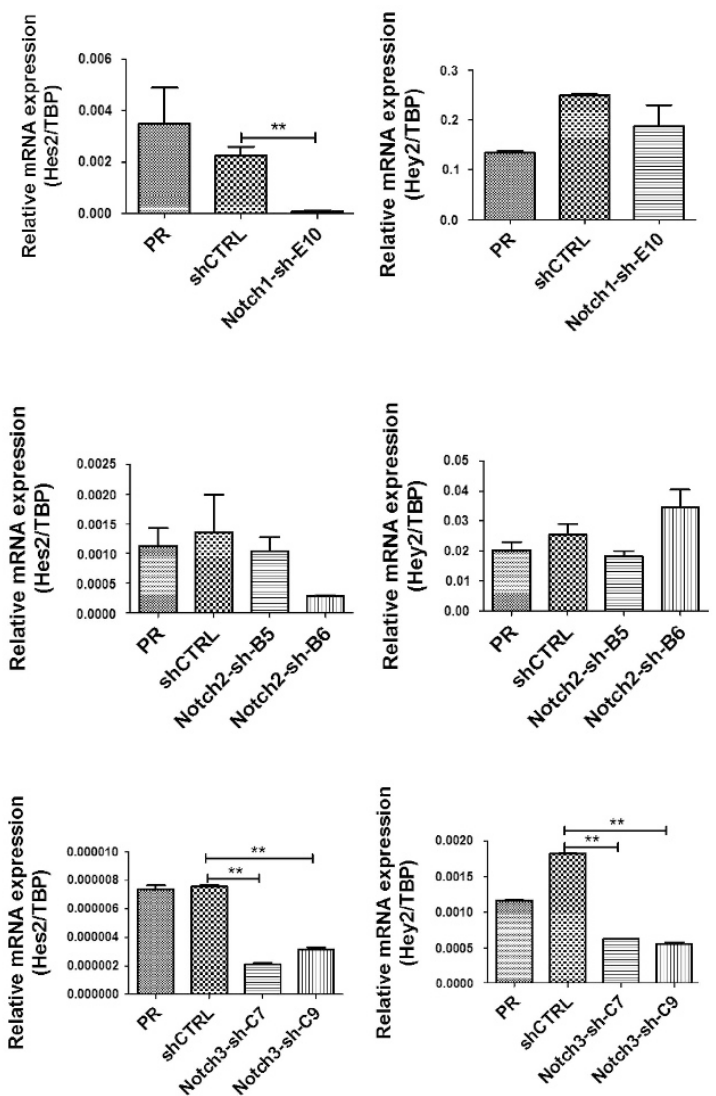

d

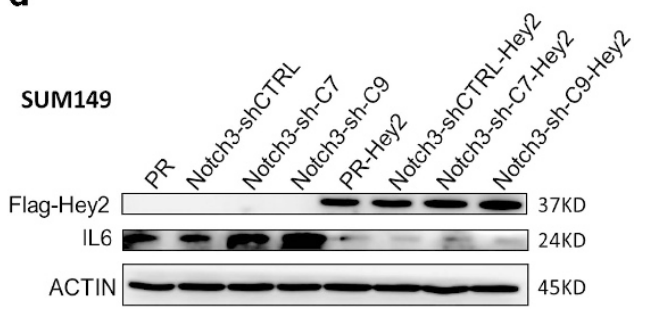

e

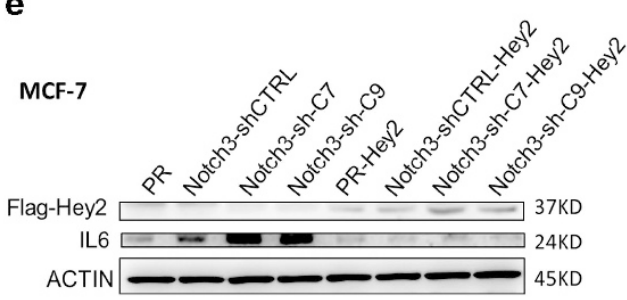

f

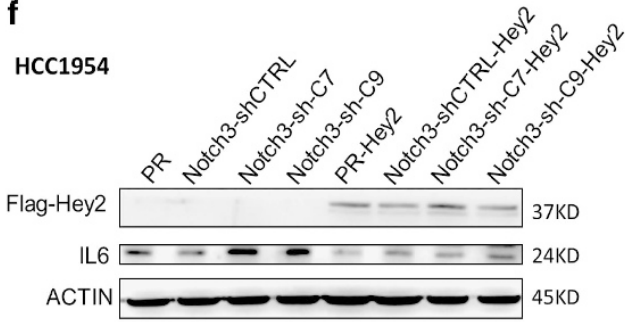

Figure 3 Hey2 mediates the IL6 induction by Notch3 knockdown. (a-c) The downstream genes of Notch were detected by using qRT-PCR in Notch1 knockdown cell lines (a), Notch2 knockdown cell lines (b) and Notch3 knockdown cell lines (c). ${ }^{*} P<0.05,{ }^{* \star} P<0.01$, ${ }^{* \star *} P<0.001$. (d-f) The Hey2 and IL6 levels were detected in each group of SUM149, MCF-7 and HCC1954 cells by using western blot analysis

knockdown also induced IL6 expression (Supplementary Figure 15b). Furthermore, we overexpressed Hey2 in Notch3 knockdown cells and demonstrated that Hey2 overexpression abrogated IL6 induction resulting from Notch3 knockdown (Figures $3 d-f$ ), thus indicating that Notch3 inhibition induces IL6 via Hey2 downregulation.

The IL6R antagonist TCZ enhances the therapeutic efficacy of the pan-Notch inhibitor MK-0752 by targeting CD24 $^{-}$CD44 $^{+}$BCSCs. According to the results described above, because the poor treatment efficacy of MK-0752 on breast cancer reflects IL6 induction by Notch3 inhibition, which was abolished via TCZ in vitro, the combination of MK-0752 and TCZ might be a better treatment strategy for the Notch3-expressing breast cancers. Tumor xenografts were established with either breast cancer cell line SUM149 or patient-derived xenograft (PDX) USTC8 $\left(\mathrm{ER}^{+}, \mathrm{PR}^{+}, \mathrm{Her}^{+}\right.$) with high Notch3 expression (Supplementary Figure 16), and mice bearing tumors were treated with MK-0752, TCZ or their combination after the average size of the tumors had reached $3 \mathrm{~mm}$ in diameter. Compared with TCZ or MK-0752 alone, the combination of MK-0752 and TCZ significantly inhibited tumor growth of both the SUM149 xenografts and PDX USTC8 (Figures 4a and b; Supplementary Figures 17a,b). Furthermore, the BCSC populations were analyzed by using flow cytometry. TCZ alone had no significant effect on the percent of $\mathrm{CD}_{24}{ }^{-} \mathrm{CD} 44^{+}$cells, MK-0752 increased percentage of $\mathrm{CD} 24^{-} \mathrm{CD} 44^{+}$cells, and the combination of MK-0752 and TCZ resulted in a $60 \%$ decrease in the CD24-CD44 population as compared with controls treatment in both SUM149 xenografts (Figure 4c) and PDX USTC8 (Figure 4d). To further assess the effects of MK-0752 and TCZ on the CSC population, we determined the ability of serial dilutions of cells obtained from primary tumors to form tumors in secondary nude mice. Cells isolated from tumors of MK-0752 treated tumors showed a markedly higher tumor-initiating capacity in secondary mice; however, the combination treatment significantly decreased their tumor-initiating capacity (Figures $4 \mathrm{e}$ and $\mathrm{f}$ ). These functional assays enabled the calculation of the frequency of tumor-initiating cells. The combination treatment decreased the CSC frequency, thus supporting the results from $\mathrm{CD} 24^{-} \mathrm{CD} 44^{+}$analysis. These results indicated that MK-0752 decreases primary tumor formation by mainly targeting bulk tumor cells and partial BCSCs in Notch3-expressing tumors and that the combination therapy of MK-0752 and TCZ decreases primary tumors by targeting both bulk tumor cells and BCSCs, thus demonstrating that the IL6R antagonist TCZ increases the efficacy of the pan-Notch inhibitor MK-0752 by blocking the IL6-dependent increase in the BCSC population. 

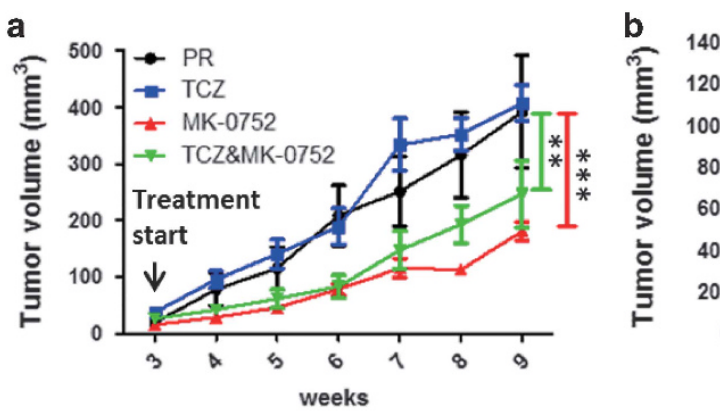

d

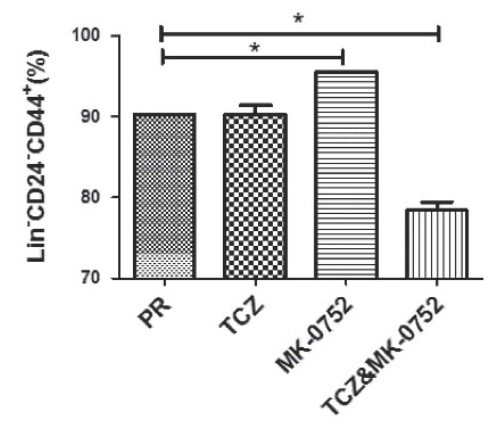

e

\begin{tabular}{|c|c|c|c|c|c|c|}
\hline \multirow{3}{*}{ Group } & \multirow{2}{*}{\multicolumn{2}{|c|}{$\begin{array}{l}\text { Limiting Dilutions } \\
\text { Tumors/Implantation }\end{array}$}} & \multirow{3}{*}{$\begin{array}{c}\text { CSC } \\
\text { Frequency(1 in ...) }\end{array}$} & \multicolumn{2}{|c|}{$\begin{array}{l}\text { Pairwise groups } \\
\text { difference }\end{array}$} & \multirow{3}{*}{\begin{tabular}{|c|} 
P Value \\
1 \\
$7.1 \mathrm{e}-05$ \\
\end{tabular}} \\
\hline & & & & PR & TCZ & \\
\hline & 500 & 5000 & & PR & MK-0752 & \\
\hline PR & $2 / 6$ & $3 / 6$ & 4739 & PR & $\begin{array}{c}\text { TCZ\&MK- } \\
0752\end{array}$ & 0.0474 \\
\hline TCZ & $2 / 6$ & $3 / 6$ & 4739 & TCZ & MK-0752 & 7.1e-05 \\
\hline MK-0752 & $5 / 6$ & $6 / 6$ & 279 & TCZ & $\begin{array}{c}\text { TCZ\&MK- } \\
0752\end{array}$ & 0.0474 \\
\hline $\begin{array}{c}\text { TCZ\&MK- } \\
0752\end{array}$ & $0 / 6$ & $1 / 6$ & 30432 & MK-0752 & $\begin{array}{l}\text { TCZ\&MK- } \\
0752\end{array}$ & $6.35 e-08$ \\
\hline
\end{tabular}

\begin{tabular}{|c|c|c|c|c|c|c|}
\hline \multirow{3}{*}{ Group } & \multirow{2}{*}{\multicolumn{2}{|c|}{$\begin{array}{l}\text { Limiting Dilutions } \\
\text { Tumors/Implantation }\end{array}$}} & \multirow{3}{*}{$\begin{array}{c}\operatorname{CSC} \\
\text { Frequency( } 1 \text { in ...) }\end{array}$} & \multicolumn{2}{|c|}{$\begin{array}{l}\text { Pairwise groups } \\
\text { difference }\end{array}$} & \multirow{3}{*}{$\begin{array}{c}\text { P Value } \\
1 \\
0.0782\end{array}$} \\
\hline & & & & \multirow{2}{*}{$\begin{array}{l}\text { PR } \\
P R\end{array}$} & \multirow{2}{*}{$\begin{array}{c}\text { TCZ } \\
\text { MK-0752 }\end{array}$} & \\
\hline & 500 & 5000 & & & & \\
\hline PR & $1 / 6$ & $2 / 6$ & 9097 & PR & $\begin{array}{c}\text { TCZ\&MK- } \\
0752\end{array}$ & 0.260 \\
\hline TCZ & $1 / 6$ & $2 / 6$ & 9097 & TCZ & MK-0752 & 0.0782 \\
\hline MK-0752 & $3 / 6$ & $4 / 6$ & 2767 & TCZ & $\begin{array}{c}\text { TCZ\&MK- } \\
0752\end{array}$ & 0.260 \\
\hline $\begin{array}{l}\text { TCZ\&MK- } \\
0752\end{array}$ & $0 / 6$ & $1 / 6$ & 30432 & MK-0752 & $\begin{array}{c}\text { TCZ\&MK- } \\
0752\end{array}$ & 0.00513 \\
\hline
\end{tabular}

Figure 4 The IL6R antagonist Tocilizumab (TCZ) abrogates the increase in CD24 $4^{-}$CD44 $4^{+}$BCSCs after pan-Notch inhibitor MK-0752 treatment and enhances the anti-tumor efficacy of MK-0752. (a,b) SUM149 cells or Lin cells sorted from PDX USTC8 were injected into both sides of the 4th mammary gland fatpads of the nude mice (4000 cells per injection site for SUM149 and 0.3 million cells per injection site for USTC8). The tumors were treated with vehicle control (PR), TCZ, MK-0752 or TCZ combined with MK-0752. The tumor size of SUM149 (a) and USTC8 (b) were monitored, measured weekly, and calculated with the formula tumor volume $=$ length $\times$ width ${ }^{2} / 2$. ${ }^{\star} P<0.05$, ${ }^{* \star} P<0.01$, ${ }^{* \star \star} P<0.001$. (c, d) The tumors in a and $\mathbf{b}$ were dissociated into single cells and were analyzed for $\mathrm{Lin}^{-} \mathrm{CD} 24^{-} \mathrm{CD} 44^{+}$by using flow cytometry. ${ }^{*} P<0.05$. (e,f) The tumor cells from $\mathbf{a}$ (e) or from b (f) were used for secondary tumor formation and the frequency of CSC was calculated on basis of the website http://bioinf.wehi.edu.au/. A total of 5000 and 500 living tumor cells were sorted and counted by using flow cytometry and were injected into both sides of the 4th mammary gland fatpads of three nude mice. The duration of secondary tumor formation was 10 weeks

HIF1a regulates Notch3 expression by directly binding to the promoter region of Notch3 and subsequently downregulates IL6. Tumors typically reside in hypoxic microenvironments in vivo. Previous studies have suggested that there are links between tumor hypoxia and Notch pathway activation $^{23}$ and that $\mathrm{BCSCs}$ are regulated by oxygen tension. ${ }^{24}$ However, it is not clear whether Notch3 plays the same roles in regulating BCSCs under hypoxic conditions. We demonstrated that cultures of SUM149 or MCF-7 breast cancer cells, which had high levels of endogenous Notch3 expression, under hypoxic conditions had significantly increased the expression of Notch3 and downstream genes (Figure 5a; Supplementary Figures 18a,b). The effects of hypoxia are often mediated by HIF1a. Hypoxia indeed increased the level of HIF1a, as determined by western blotting in the present study (Supplementary Figure 18c). Previous studies have demonstrated that hypoxia promotes tumor growth by increasing cancer stem cells. ${ }^{24}$ However, here, we showed that hypoxia decreased the CD24-CD $44^{+}$ breast cancer stem cell population (Figure 5b; Supplementary Figure 18d) and had little effect on the $\mathrm{ALDH}^{+}$breast cancer stem cell population (data not shown) in SUM149 and MCF-7. To determine whether these contradictions might be reflected by the high Notch3 expression in the analyzed breast cancer cells, we investigated the effects of hypoxia on the BCSC population in the low Notch3- 

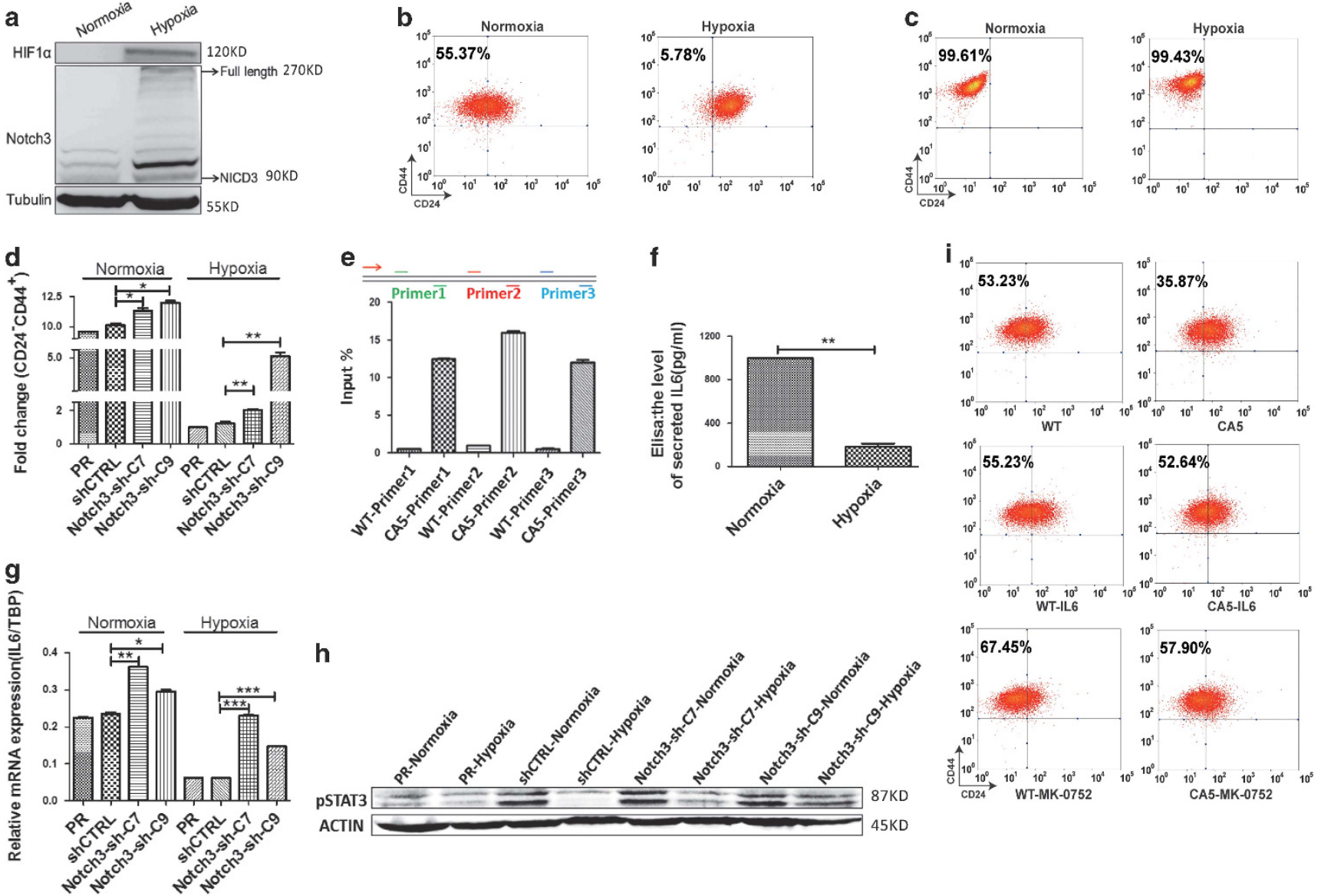

Figure 5 HIF1 $\alpha$ regulates Notch3 expression by binding directly to the promoter region of Notch3 and subsequently downregulates IL6. (a). SUM149 was cultured under normoxic $\left(20 \% \mathrm{O}_{2}\right)$ or hypoxic $\left(1 \% \mathrm{O}_{2}\right)$ conditions for 7 days. The protein levels of Notch3 and NICD3 were detected by using Western blot analysis. (b,c) The CD24-CD44 ${ }^{+}$cell population was detected by using flow cytometry in SUM149 (b) and MDAMB231 (c) cultured under hypoxic conditions for 7 days. (d). The CD24-CD44 ${ }^{+}$cell population was detected by using flow cytometry in Notch3 knockdown cells of SUM149 cultured under hypoxic conditions for 7 days. ${ }^{*} P<0.05,{ }^{* \star} P<0.01,{ }^{* \star *} P<0.001$. (e) The ChIP assay showed that HIF1 $\alpha$ might directly bind to the Notch3 promoter region.CA5: stabilized truncation of HIF1 $\alpha$ in SUM149. (f) Hypoxia downregulates IL6 at the protein level, as detected through ELISA in SUM149. ${ }^{*} P<0.05,{ }^{* *} P<0.01,{ }^{* * *} P<0.001$. (g, h) IL6 mRNA expression (g) and the pSTAT3 level (h) were detected by using qRT-PCR and western blot analysis accordingly in Notch3 knockdown cells of SUM149 cultured under hypoxic conditions for one week. ${ }^{\star} P<0.05,{ }^{* \star} P<0.01,{ }^{\star \star \star} P<0.001$. (i) $\mathrm{CD} 24^{-} \mathrm{CD} 44^{+}$cell population was analyzed by using flow cytometry with the SUM149 cell treated with MK-0752 or IL6

expressing cell lines MDA-MB-231 and SUM159, and found that hypoxia induced $\mathrm{ALDH}^{+} \mathrm{BCSCs}$, but had little effect on CD24-CD44+ ${ }^{+}$BCSCs (Figure 5c; Supplementary Figures $19 a, b)$. Although hypoxia also induced Notch3 expression in MDA-MB-231 cells (Supplementary Figure 20a), as measured by using qRT-PCR, the expression level was very low (PCR cycle number is over 30), thus suggesting an insufficiency of IL6 inhibition (Supplementary Figure 20b). As shown in Figure $5 d$, Notch3 knockdown abrogated the effects of hypoxia on the CD24-CD $44^{+}$BCSC population. To determine whether the effects of hypoxia on Notch3 expression and the BCSC population were mediated by HIF1a, we generated a HIF1a knockdown cell line of SUM149. In contrast to that in parental or scrambled knockdown control cells, Notch3 expression was much lower in cells exposed to hypoxia (Supplementary Figure 18c) and hypoxia did not decrease the CD24-CD44 ${ }^{+}$BCSC population in HIF1a knockdown cells (Supplementary Figure 21). To further investigate the role of HIF1a in mediating the effects of tumor hypoxia, we established a cell line that constitutively expressed active stabilized HIF1a, CA $5^{25}$ and observed that CA5 constitutively activated Notch3 signaling and decreased the CD24-CD44 ${ }^{+}$population (Supplementary Figures 22a,b). These results demonstrated that tumor hypoxia regulates Notch3 expression and the $\mathrm{CD} 24^{-} \mathrm{CD} 44^{+} \mathrm{BCSC}$ population in a process dependent on HIF1a. Furthermore, bioinformatics analysis identified 15 potential binding sites of HIF1a within $1000 \mathrm{bp}$ upstream of the Notch3 coding region, thus suggesting that HIF1a might directly bind to the promoter of Notch3 and regulate Notch3 expression (Supplementary Figure 23). We designed three pairs of primers that were complementary to the Notch3 promoter to determine whether HIF1a directly interacts with the Notch3 promoter. As demonstrated by the CHIP-qRT-PCR assay for the interaction of the HIF1a protein and Notch3 promoter, there was an enrichment of the Notch3 promoter in CA5-overexpressing cells compared with the controls, as determined by using qRT-PCR (Figure 5e). These results suggested that HIF1a transcriptionally regulates Notch3 expression by directly binding to its promoter. 
Because these studies demonstrated that hypoxia regulates Notch3 expression and Notch3 regulates IL6, we determined whether the IL6 pathway might have a role in mediating the effects of hypoxia on Notch3-expressing breast cancer cells. Both the qRT-PCR and ELISA results showed that hypoxia significantly decreased IL6 production in breast cancer cells (Figure 5f; Supplementary Figure 24a), and there was a subsequent decrease in pSTAT3 expression (Supplementary Figure 24b). Interestingly, this inhibition was abrogated by HIF1a knockdown (Supplementary Figure 24c). Furthermore, we observed that Notch3 knockdown abolished the downregulation effect of hypoxia on IL6 in both SUM149 and MCF-7 cells (Figure 5g; Supplementary Figure 25) and Notch3 knockdown effectively upregulated the pSTAT3 level (Figure 5h). To determine whether IL6 addition might antagonize the hypoxia/HIF1a effect on the CD24-CD44 ${ }^{+}$ population, we treated CA5-expressing cells with MK-0752 or IL6, and observed that both treatments blocked the effect of hypoxia and rescued the decrease in the $\mathrm{CD} 24^{-} \mathrm{CD} 44^{+}$ population (Figure 5i). Altogether, these findings suggested that hypoxia regulates the $\mathrm{CD} 24^{-} \mathrm{CD} 44^{+} \mathrm{BCSC}$ s population under the regulation of the HIF1a-Notch3-IL6 signaling axis.

\section{Discussion}

Although most studies have emphasized the tumor-promoting role of Notch receptors ${ }^{5}$ and a recent report has shown that Notch3 promotes the proliferation of basal type breast cancer without emphasizing the effect of Notch3 on breast cancer stem cells, ${ }^{26}$ a number of recent studies have indicated that Notch signaling can also have a tumor suppressive function. ${ }^{27}$ Although there is evidence that different Notch receptors may have divergent functions, most previous studies have focused on the Notch1 or Notch2 receptors ${ }^{28}$ and some previous studies had not indicated which Notch receptor has a major role in cancer. ${ }^{29}$ There are considerably fewer studies on Notch3, although there are reports of Notch3 functioning in cellular senescence. ${ }^{30}$

Because the Notch signaling pathway contributes to tumorigenesis, a number of Notch inhibitors have entered early phase clinical trials. Some of these compounds, such as GSIs, promiscuously inhibit all four Notch receptors. However, in addition to potentially increasing toxicity, simultaneous inhibition of multiple Notch inhibitors may have pleiotropic effects that may stimulate tumor growth. ${ }^{11}$ In breast cancer, Notch3 knockdown decreases cellular senescence and NICD3 overexpression inhibits the growth of cancer cells. ${ }^{30}$ This finding suggests that different Notch receptors may have different effects on tumors, thus limiting the effect of pan-Notch inhibitors on tumors. Although the present study was conducted in a different tumor type, these results might provide clues explaining the failure of a recent clinical trial in advanced pancreatic cancer employing an antibody that inhibits both Notch2 and Notch3 (Oncomed Pharmaceuticals). We observed that MK-0752 upregulates BCSCs through upregulation of IL6 expression, a finding that prompted us to explore the role of Notch3-IL6 in the upregulation of CSC by MK-0752.

He et al. have indicated that high expression of IL6 or IL8 abrogates the anti-tumor effect of RO4929097 in lung cancer and gliomas. ${ }^{15}$ However, we did not know whether it is the same case in breast cancer and did not know the underlying mechanism. IL6, a cytokine that has an important role in BCSC regulation, has inflammatory or anti-inflammatory properties. $^{31-33} \mathrm{Jin}$ et al. and others have reported that overexpression of NICD1 increases expression of IL6, with subsequent phosphorylation of STAT3. ${ }^{20,34}$ IL6 has been shown to upregulate Notch3. ${ }^{18,35}$ However, the underlying mechanisms remain undefined. The present study further demonstrated that the effects of Notch3 on the CD24-CD44 ${ }^{+}$ cell population are mediated by IL6. This regulation may be related to downstream targets of Notch3, the Hes and Hey families which have been shown to negatively modulate genes in the Achaete-Scute family. ${ }^{36}$ These findings demonstrated that IL6 is one of the downstream genes regulated by the Hey2 transcription factor.

The Notch signaling pathway is also involved in intercellular communication within the tumor microenvironment. ${ }^{37}$ For example, in areas of hypoxia in the tumor interior, the labile protein HIF1a is stabilized, thus leading to activation of a number of downstream pathways, including Notch ${ }^{38,39}$ which promotes cell migration, an important component of metastasis. ${ }^{40,41}$ Here, we provide evidences that Notch3 has a role in the response of tumor cells to hypoxia. Hypoxia stabilizes HIF1 $a$ and subsequently upregulates Notch3, which in turn downregulates IL6. In addition, we demonstrated that hypoxia/HIF1a decreases the $\mathrm{CD}_{24}{ }^{-} \mathrm{CD} 44^{+}$population via Notch3-IL6 pathway.

Importantly, we demonstrated that the IL6-dependent increase in $\mathrm{CD}_{24}{ }^{-} \mathrm{CD} 44^{+} \mathrm{BCSC}$ generated by Notch inhibition can be abrogated by the IL6R blocking antibody Tocilizumab. This agent is FDA-approved for the treatment of rheumatoid arthritis. Thus, the results of the present study suggest that the addition of Tociluzumab to pan-Notch inhibitors may represent a rational therapeutic approach.

\section{Materials and Methods}

Clinical breast tumor samples. All of the clinical breast tumor samples were obtained from the Shanghai Cancer Hospital, which is affiliated with Fudan University. Clinical pathologists evaluated Notch3 and IL6 immunohistochemistry staining. The Notch3 and IL6 scores were defined on the basis of the membrane/ cytoplasm staining ( $0=$ negative; $1=$ weak; $2=$ moderate; and $3=$ strong).

Cell culture. Breast cancer cell lines SUM149 and SUM159 were obtained from Asterland. MDA-MB-231, MCF-7 and HCC1954 cells were cultured according to the ATCC recommendations. All cell lines were obtained from ATCC or Asterland before initiation of these studies, and their identity was routinely monitored through STR profiling.

Chemicals. Gamma secretase inhibitors (MK-0752, R04929097) were purchased from Selleck and dissolved in DMSO to make a $10 \mathrm{mM}$ stock solution. The effective concentration of MK-0752 (RO4929097) was $25 \mu \mathrm{M}(10 \mu \mathrm{M})$ for in vitro cell culture. Tocilizumab (TCZ) was purchased from Roche (Shanghai, China) and the effective concentration of TCZ was $10 \mu \mathrm{g} / \mathrm{ml}$ for in vitro cell culture.

Sphere-forming assay. SUM149 and MCF-7 cells were plated at 30000 cells per well onto 6-well ultra-low attachment plates (Corning, Shanghai, China). The cells were cultured in complete medium $(50 \mathrm{ml}$ medium containing $44.5 \mathrm{ml}$ MammoCult Basal Medium supplemented with $5 \mathrm{ml}$ MammoCult Proliferation Supplement, $100 \mu \mathrm{l}$ Heparin, $24 \mu \mathrm{l}$ Hydrocortisone $(1 \mu \mathrm{g} / \mathrm{ml})$, and $0.5 \mathrm{ml}$ Pen-strep) (STEMCELL) for 7 days. 
Western blot analysis. Total cell protein was extracted from boiling SDS sample buffer ( $2 \%$ SDS, $50 \mathrm{mM}$ Tris- $\mathrm{HCl}, \mathrm{pH} 6.8,10 \%$ glycerol, $0.002 \%$ bromophenol blue, and 6\% 2-mercaptoethanol). Protein lysates were separated by SDS-PAGE and subsequently transferred to polyvinylidene difluoride membranes (Millipore). The membranes were blocked in TBS-T buffer (10 mM Tris-HCl, pH 7.4, $150 \mathrm{mM} \mathrm{NaCl}$, and $0.05 \%(\mathrm{v} / \mathrm{v})$ Tween 20 ) containing $5 \% \mathrm{BSA}$ and probed with primary antibodies in blocking buffer at $4{ }^{\circ} \mathrm{C}$ overnight. The blots were washed with TBS-T buffer and incubated with secondary antibodies diluted in BSA at room temperature for $1 \mathrm{~h}$. The primary antibodies used in the present study were antiNotch1, anti-Notch2, anti-Notch3, anti-Notch4, anti-STAT3, anti-pSTAT3 (CST), antiHIF1 $\alpha(B D)$, anti-Actin and anti-Tubulin (Transgene) antibodies. All of the secondary antibodies were purchased from Santa Cruz Biotechnology (Santa Cruz, CA, USA).

MTT cell proliferation assay. A total of 500 cells were seeded onto each well of a 96-well culture and cultured for $1,3,5$ or 7 days. Subsequently, $0.025 \mathrm{ml}$ of MTT solution (Biosharp: $5 \mathrm{mg} / \mathrm{ml}$ ) was added to each well, and the cells were incubated for $3 \mathrm{~h}$. The supernatant was removed from each well, DMSO was added (100 $\mu /$ well), and the optical density (OD) value was measured at $490 \mathrm{~nm}$ after $15 \mathrm{~min}$.

Quantitative chromatin immunoprecipitation analysis. Quantitative ChIP analysis was performed as previously described. ${ }^{31}$ Cells were cultured in a $150 \mathrm{~mm}$ dish at $80-90 \%$ confluency. The beads were purchased from Invitrogen. The antibody of against HIF1 $\alpha(\mathrm{BD})$ was used to pull down the DNA and protein, and the purified DNA was used to perform qRT-PCR. We designed three pairs of primers targeted to different regions of the Notch3 promoter for use in qRT-PCR: $f$ GGGCACAGGTCCTTGATGTA, r-GGCATGCAGGGAAAAGTGTC;

primer2: f-GACTCAGTGGCAATGGGGAG, r-CCCACTTAGAGGAGGTTGGC; primer3: f-GGAGTCAGAGGAACTCAGTTCA, r-AAAGCTGAAGTCATGCACGAAG

Enzyme-linked immunosorbent assay. A human IL6 ELISA kit was purchased from RayBiotech (Norcross, GA, USA). The cells were cultured in 6-well dishes and the culture density did not exceed eighty percent. After $48 \mathrm{~h}$, the culture medium was collected to measure the secreted IL6 levels. The procedure is summarized here: (1) all reagents, samples and standards were prepared as instructed; (2) $100 \mu \mathrm{l}$ of standard or sample was added to each well and were incubated for $2.5 \mathrm{~h}$ at room temperature or overnight at $4^{\circ} \mathrm{C}$; (3) $100 \mu \mathrm{l}$ of the prepared biotin antibody was added to each well and incubated for $1 \mathrm{~h}$ at room temperature; (4) $100 \mu \mathrm{l}$ of the prepared Streptavidin solution was added and incubated for $45 \mathrm{~min}$ at room temperature; (5) $100 \mu \mathrm{l}$ of TMB One-Step Substrate Reagent was added to each well and incubated for $30 \mathrm{~min}$ at room temperature; (6) $50 \mu \mathrm{l}$ of Stop Solution was added to each well, and plates were immediately read at $450 \mathrm{~nm}$.

Real-time quantitative PCR. The mRNA expression level was measured by using qRT-PCR. Single-stranded CDNA was synthesized from $1 \mu \mathrm{g}$ of total RNA in a volume of $20 \mu \mathrm{L}$ according to the manufacturer's instructions (TOYOBO), and $2 \mu \mathrm{L}$ of CDNA was used as template in subsequent real-time PCR reactions conducted on an ABI7300 using SYBR GreenSuperMix with ROX kit (Vazyme) according to the manufacturer's instructions at a final volume of $20 \mu \mathrm{L}$. The following primers were used: IL1 $\alpha$ : f-CCACTCCATGAAGGCTGCATG, r-GGTGCTGACCTAGGCTTGATG; IL6: f-AGTGGCTGCAGGACATGACAA, r-CAATCTGAGGTGCCCATGCTA; CCL3:fCGGTGTCATCTTCCTAACCA, r-GACATATTTCTGGACCCACTC; CCL5: f-TACCAT GAAGGTCTCCGC, r-GACAAAGACGACTGCTGG; CCL20: f-TCCTGGCTGCTTT GATGTCA, r-CAAAGTTGCTTGCTGCTTCTGA; Notch3:f-CGTGGCTTCTTTCTA CTGTGC, r-CGTTCACCGGATTTGTGTCAC; Hes1: f-CGATGGCCAGTTTGCTTT, r-TGGAAGGTGACACTGCGTT; Hes2: f-CAGCTTAAGGGGCTCATCCT, r-GAAGC GCACGGTCATTTC; Hes7: f-AAGCTGGAGAAAGGGAGA; r-GAAACCGGAC AAGTAGCAGC; Hey1: f-TTGGCCAGAAAAGACGG, r-ATCTGCAGGATCT CGGCTT; Hey2: f-GCTCTTGCCATGGACTTCA, r-AGATGAGACACAAGCCGCA; TBP: f-TGCACAGGAGCCAAGAGTGAA, r-CACATCACAGCTCCCCACCA; GAP DH: f-GGTCTCCTCTGACTTCAACA, r-AGCCAAATTCGTTGTCATAC.

Flow cytometry. The tumors were digested with collagenase for $1 \mathrm{~h}$ and shaken every $15 \mathrm{~min}$. Subsequently, the mixture was filtered by using $40-\mu \mathrm{m}$ cell strainer (Biologix) (Jinan, Shandong, China) to obtain a single cell suspension. Ammonium chloride solution (Stem cell) was added to lyse red blood cells. The cell lines were digested by using $0.05 \%$ Trypsin and washed with PBS containing $2 \%$ FBS. The cells were re-suspended in PBS containing $2 \%$ FBS and incubated with antibodies on ice for $30 \mathrm{~min}$. Subsequently, the cells were washed 3 times with PBS containing $2 \%$ FBS. Before analysis at MoFlo Astrios, the cells were re-suspended in PBS containing $2 \% \mathrm{FBS}$ and $1 \mu \mathrm{g} / \mathrm{ml} \mathrm{DAPI}$. The following antibodies were used: PE-conjugated anti-Notch3 (Biolegend, 1:40), APC-conjugated anti-CD24 (Biolegend, 1:40), APC-H7-conjugated anti-CD44 (BD, 1:100), PE-conjugated anti-CD45 (BD, 1:50), PE-conjugated anti-CD31 (BD, 1:50), PE-conjugated anti-CD140b (BD, 1:50), PE-conjugated anti-CD235a (BD, 1:50) and PE-conjugated anti-H2KD (Biolegend, 1:100).

Immunohistochemistry. Paraffin-embedded sections of breast tumors from xenografts were de-paraffinized in xylene and rehydrated in graded alcohol. For antigen enhancement, the sections were incubated in $10 \mathrm{mmol} / \mathrm{l}$ citrate buffer, $\mathrm{pH} 6$. $0^{42}$ (Dakocytomation, Copenhagen, Denmark) according to the manufacturer's instructions. The primary antibodies used were anti-Notch3 antibody (CST, 1:75 dilution) and anti-IL6 antibody (Genetex, 1:100 dilution). The secondary antibodies used were goat anti-mouse/rabbit IgG conjugated with Polymer-HRP. Immunoreactivity was detected using $3,3^{\prime}$-diaminobenzidine substrate. The sections were examined with an EVOS microscope.

In vivo tumorigenicity. Three-week-old female nude mice were obtained from Vital River and housed in AAALAC-accredited specific-pathogen-free rodent facilities at the University of Science and Technology of China. All mouse experiments were conducted in accordance with standard operating procedures approved by the University Committee on the Use and Care of Animals at University of Science and Technology of China. Drug treatments were initiated when the tumors reached an average diameter of $3 \mathrm{~mm}$ (TCZ was administered at $10 \mathrm{mg} / \mathrm{kg}$, once per week, i.p.; and MK-0752 (dissolved in 30\% propylene, $5 \%$ Tween $80,65 \%$ D5W) was administered at $25 \mathrm{mg} / \mathrm{kg}$; twice per week, i.g.). The animals were euthanized when the treatments were ended. The tumor sizes were measured twice a week with a caliper, and calculated as tumor volume $=$ Length $\mathrm{x}$ Width $^{2} / 2$.

Statistical analysis. The results are presented as the means \pm S.D. of at least three repeated individual experiments for each group. Significant differences were determined by using ANOVA and Student's t-test for independent samples. A $P$ value of less than 0.05 was considered statistically significant.

\section{Conflict of Interest}

MSW has financial holdings and is a scientific advisor for OncoMed Pharmaceuticals, is a scientific advisor for Verastem, Paganini and Medlmmune and receives research support from Dompe Pharmaceuticals and Medlmmune. The remaining authors declare no conflict of interest.

Acknowledgements. Thanks to Dr Stephen Ethier for generously providing the breast cancer cell line SUM149. This work was supported by NSFC grant (81530075), the National Key Research and Development Program of China (Stem Cell and Translational Research 2016YFA0101202), the MOST grant (2015CB553800), NSFC grants ( 81472741 and 81322033 ), the CAS stem cell grant (XDA01040410), and the Fundamental Research Funds for the Central Universities (WK2070000034).

1. Chiba S. Notch signaling in stem cell systems. Stem Cells 2006; 24: 2437-2447.

2. Fre $S$, Huyghe $M$, Mourikis $P$, Robine $S$, Louvard D, Artavanis-Tsakonas S. Notch signals control the fate of immature progenitor cells in the intestine. Nature 2005; 435 : 964-968.

3. van Es JH, van Gijn ME, Riccio O, van den Born M, Vooijs M, Begthel H et al. Notch/gammasecretase inhibition turns proliferative cells in intestinal crypts and adenomas into goblet cells. Nature 2005; 435: 959-963.

4. Hassan KA, Wang L, Korkaya H, Chen G, Maillard I, Beer DG et al. Notch pathway activity identifies cells with cancer stem cell-like properties and correlates with worse survival in lung adenocarcinoma. Clin Cancer Res 2013; 19: 1972-1980.

5. Ali SA, Justilien V, Jamieson L, Murray NR, Fields AP. Protein kinase ciota drives a NOTCH3-dependent stem-like phenotype in mutant KRAS lung adenocarcinoma. Cancer Cell 2016; 29: 367-378.

6. Harrison H, Farnie G, Howell SJ, Rock RE, Stylianou S, Brennan KR et al. Regulation of breast cancer stem cell activity by signaling through the Notch4 receptor. Cancer Res 2010; 70: 709-718.

7. Yap LF, Lee D, Khairuddin A, Pairan MF, Puspita B, Siar CH et al. The opposing roles of NOTCH signalling in head and neck cancer: a mini review. Oral Dis 2015; 21: 850-857. 
8. Nagamatsu I, Onishi H, Matsushita S, Kubo M, Kai M, Imaizumi A et al. NOTCH4 is a potential therapeutic target for triple-negative breast cancer. Anticancer Res 2014; 34: 69-80.

9. Bu P, Chen KY, Chen JH, Wang L, Walters J, Shin YJ et al. A microRNA miR-34a-regulated bimodal switch targets Notch in colon cancer stem cells. Cell Stem Cell 2013; 12: 602-615.

10. Zhou ZC, Dong QG, Fu DL, Gong YY, Ni QX. Characteristics of Notch2(+) pancreatic cancer stem-like cells and the relationship with centroacinar cells. Cell Biol Int 2013; 37: 805-811.

11. Espinoza I, Miele L. Notch inhibitors for cancer treatment. Pharmacol Ther 2013; 139: 95-110.

12. Schott AF, Landis MD, Dontu G, Griffith KA, Layman RM, Krop I et al. Preclinical and clinical studies of gamma secretase inhibitors with docetaxel on human breast tumors. Clin Cancer Res 2013; 19: 1512-1524.

13. Chen X, Gong L, Ou R, Zheng Z, Chen J, Xie F et al. Sequential combination therapy of ovarian cancer with cisplatin and gamma-secretase inhibitor MK-0752. Gynecol Oncol 2016; 140: $537-544$.

14. Wei $P$, Walls M, Qiu M, Ding R, Denlinger RH, Wong A et al. Evaluation of selective gammasecretase inhibitor PF-03084014 for its antitumor efficacy and gastrointestinal safety to guide optimal clinical trial design. Mol Cancer Ther 2010; 9: 1618-1628.

15. He W, Luistro L, Carvajal D, Smith M, Nevins T, Yin X et al. High tumor levels of IL6 and IL8 abrogate preclinical efficacy of the gamma-secretase inhibitor, RO4929097. Mol Oncol 2011; 5: 292-301.

16. Liu S, Ginestier C, Ou SJ, Clouthier SG, Patel SH, Monville F et al. Breast cancer stem cells are regulated by mesenchymal stem cells through cytokine networks. Cancer Res 2011; 71: 614-624.

17. Coussens LM, Werb Z. Inflammation and cancer. Nature 2002; 420: 860-867.

18. Jin S, Mutvei AP, Chivukula IV, Andersson ER, Ramskold D, Sandberg R et al. Noncanonical Notch signaling activates IL-6/JAK/STAT signaling in breast tumor cells and is controlled by p53 and IKKalpha/IKKbeta. Oncogene 2013; 32: 4892-4902.

19. Reedijk M, Odorcic S, Chang L, Zhang H, Miller N, McCready DR et al. High-level coexpression of JAG1 and NOTCH1 is observed in human breast cancer and is associated with poor overall survival. Cancer Res 2005; 65: 8530-8537.

20. Sethi N, Dai X, Winter CG, Kang Y. Tumor-derived JAGGED1 promotes osteolytic bone metastasis of breast cancer by engaging notch signaling in bone cells. Cancer Cell 2011; 19 : 192-205.

21. Sansone $P$, Ceccarelli C, Berishaj M, Chang Q, Rajasekhar VK, Perna F et al. Self-renewal of CD133(hi) cells by IL6/Notch3 signalling regulates endocrine resistance in metastatic breast cancer. Nat Commun 2016; 7: 10442

22. Peng D, Tanikawa T, Li W, Zhao L, Vatan L, Szeliga W et al. Myeloid-derived suppressor cells endow stem-like qualities to breast cancer cells through IL6/STAT3 and NO/NOTCH crosstalk signaling. Cancer Res 2016; 76: 3156-3165.

23. Xing F, Okuda H, Watabe M, Kobayashi A, Pai SK, Liu W et al. Hypoxia-induced Jagged2 promotes breast cancer metastasis and self-renewal of cancer stem-like cells. Oncogene 2011; 30: 4075-4086.

24. Iriondo O, Rabano M, Domenici G, Carlevaris O, Lopez-Ruiz JA, Zabalza I et al. Distinct breast cancer stem/progenitor cell populations require either HIF1alpha or loss of PHD3 to expand under hypoxic conditions. Oncotarget 2015; 6: 31721-31739.
25. Gao $\mathrm{P}$, Zhang H, Dinavahi R, Li F, Xiang Y, Raman V et al. HIF-dependent antitumorigenic effect of antioxidants in vivo. Cancer Cell 2007; 12: 230-238.

26. Choy L, Hagenbeek TJ, Solon M, French D, Finkle D, Shelton A et al. Constitutive NOTCH3 signaling promotes the growth of basal breast cancers. Cancer Res 2017; 77: $1439-1452$.

27. Romer S, Saunders U, Jack HM, Jehn BM. Notch1 enhances B-cell receptor-induced apoptosis in mature activated $B$ cells without affecting cell cycle progression and surface IgM expression. Cell Death Differ 2003; 10: 833-844.

28. Benson JR, Jatoi I, Keisch M, Esteva FJ, Makris A, Jordan VC. Early breast cancer. Lancet 2009; 373: 1463-1479.

29. Debeb BG, Cohen EN, Boley K, Freiter EM, Li L, Robertson FM et al. Pre-clinical studies of Notch signaling inhibitor RO4929097 in inflammatory breast cancer cells. Breast Cancer Res Treat 2012; 134: 495-510.

30. Cui $\mathrm{H}$, Kong $\mathrm{Y}, \mathrm{Xu} \mathrm{M}$, Zhang $\mathrm{H}$. Notch3 functions as a tumor suppressor by controlling cellular senescence. Cancer Res 2013; 73: 3451-3459.

31. Dienz O, Eaton SM, Bond JP, Neveu W, Moquin D, Noubade R et al. The induction of antibody production by IL- 6 is indirectly mediated by IL-21 produced by CD4+ T cells. J Exp Med 2009; 206: 69-78.

32. Youinou $\mathrm{P}$, Jamin $\mathrm{C}$. The weight of interleukin-6 in B cell-related autoimmune disorders. $J$ Autoimmun 2009; 32: 206-210.

33. Knupfer H, Preiss R. slL-6R: more than an agonist? Immunol Cell Biol 2008; 86: 87-91.

34. Sansone P, Storci G, Tavolari S, Guarnieri T, Giovannini C, Taffurelli M et al. IL-6 triggers malignant features in mammospheres from human ductal breast carcinoma and normal mammary gland. J Clin Investig 2007; 117: 3988-4002.

35. Hao L, Rizzo P, Osipo C, Pannuti A, Wyatt D, Cheung LW et al. Notch-1 activates estrogen receptor-alpha-dependent transcription via IKKalpha in breast cancer cells. Oncogene 2010; 29: 201-213.

36. Maier MM, Gessler M. Comparative analysis of the human and mouse Hey1 promoter: Hey genes are new Notch target genes. Biochem Biophys Res Commun 2000; 275 : 652-660.

37. Gustafsson MV, Zheng X, Pereira T, Gradin K, Jin S, Lundkvist J et al. Hypoxia requires notch signaling to maintain the undifferentiated cell state. Dev Cell 2005; 9: 617-628.

38. Maxwell PH, Wiesener MS, Chang GW, Clifford SC, Vaux EC, Cockman ME et al. The tumour suppressor protein VHL targets hypoxia-inducible factors for oxygen-dependent proteolysis. Nature 1999; 399: 271-275.

39. Semenza GL. Hydroxylation of HIF-1: oxygen sensing at the molecular level. Physiology 2004; 19: 176-182.

40. Wang Y, Liu Y, Malek SN, Zheng P, Liu Y. Targeting HIF1alpha eliminates cancer stem cells in hematological malignancies. Cell Stem Cell 2011; 8: 399-411.

41. Sahlgren C, Gustafsson MV, Jin S, Poellinger L, Lendahl U. Notch signaling mediates hypoxia-induced tumor cell migration and invasion. Proc Natl Acad Sci USA 2008; 105: 6392-6397.

42. Liu S, Cong Y, Wang D, Sun Y, Deng L, Liu Y et al. Breast cancer stem cells transition between epithelial and mesenchymal states reflective of their normal counterparts. Stem Cell Rep 2014; 2: 78-91.

Supplementary Information accompanies this paper on Cell Death and Differentiation website (http://www.nature.com/cdd) 